\title{
Construction of Nickel Oxide/Nitrogen-doped Carbon Nanotubes Cata- lysts with High Activity for Oxygen Reduction Reaction
}

\author{
Pinghua YANG \& Jianping XU \\ College of Chemistry and Environment Engineering, Jiangxi Province Engineering Research Cen- \\ ter of Ecological Chemical Industry, Jiujiang University, Jiujiang, China, 332005
}

KEYWORD: Nickel oxide/nitrogen-doped carbon nanotubes; oxygen reduction reaction; Catlytic Activity

ABSTRACT: Nickel oxide/nitrogen-doped carbon nanotubes catalysts for the (ORR) were fabricated using a simple chemical plating method. Scanning electron microscopy (SEM) and Energy dispersive spectrometer (EDS) was used to characterize its structure. Electrochemical method studies show that the nickel oxide/nitrogen-doped carbon nanotubes could exhibit a high ORR activity.

\section{INTRODUCTION}

The commercial application of fuel cells has been hindered by the high cost and scarcity of the requisite noble metal materials(Winter M. \& Brodd R. J. 2004). With high activity and practical durability, the non-noble metal catalysts has been viewed as a good substitute to promote the development of fuel cells(Alexey Serov \& Chan Kwak. 2009). Various non-noble metal catalysts materials have been evaluated as potential substitutes for Pt-based catalysts(Kuanping Gong 2007). With their excellent electrocatalytic activities, nitrogen-doped carbon nanotubes have attracted attention (Yu D et al. 2010, Wang $Z$ et al. 2011). The new way to prepare of metal-free catalyst for the ORR has opened. The doping of $\mathrm{N}$ atoms play a key role in their catalytic activity enhancement toward the ORR for that their change the electronic structure of carbon nanotubes(Kurak K A \& Anderson A B 2009).

Herein, we have prepared a nickel oxide/ nitrogen-doped carbon nanotubes (NiOx/N-CNTs) composite material via a simple chemical plating method. The $\mathrm{NiOx} / \mathrm{N}-\mathrm{CNTs}$ exhibit excellent electrocatalytic activity toward the ORR in an alkaline medium.

\section{EXPERIMENTAL SECTION}

\section{Apparatus}

Scanning electron microscopy (SEM) images were obtained by using VEGA II LSU SEM (Czech TESCAN). All electrochemical experiments were carried out on a CHI660B electrochemical workstation (Chenhua Instrument Company of Shanghai, China) in a conventional three electrodes cell. The working electrode was a composite films electrode with a diameter of $3 \mathrm{~mm}$, the auxiliary electrode consisted of a platinum wire, and a saturated calomel electrode (SCE) was used as the reference electrode. All potentials reported in this paper are relative to SCE.

\section{Reagents}

Carbon nanotubes (CNTs, Shenzhen Nanotech Port Co. Ltd, China) have a typical diameter of 10-20 $\mathrm{nm}$ and length of 5-15 $\mu \mathrm{m}$. The purity was more than $97 \%$. Other chemicals were of analytical grade and were used as received. Double distilled water was used throughout the experiments. All the procedure was acted at room temperature. Oxygen was removed by purging with high-purity nitrogen for 10 minutes and a nitrogen atmosphere was kept over the solution during measurements.

\section{Synthesizing of nickel oxide/nitrogen-doped carbon nanotubes}

Firstly, their was synthesizing of nitrogen-doped carbon nanotubes. Take $100 \mathrm{~mL} \mathrm{30 \%} \mathrm{hydrazine} \mathrm{hy-}$ drate, $100 \mathrm{~mL}$ water and $600 \mathrm{mg}$ carbon nanotubes has imposed on the distillation flask. The mixture was heated to $60{ }^{\circ} \mathrm{C}$ and reflux for $6 \mathrm{~h}$, then clean the filtration with water. The filtration solid was drying to $80^{\circ} \mathrm{C}$ for $8 \mathrm{~h}$.

Nickel oxide/nitrogen-doped carbon nanotubes were prepared by chemical plating method. Firstly, $0.6 \mathrm{~g}$ functionalized $\mathrm{N}-\mathrm{CNTs}$ was mixed with $50 \mathrm{ml}$ mixture solution of $5 \mathrm{~g} / \mathrm{L}$ sodium hypophosphite, 
$1 \mathrm{~g} / \mathrm{L}$ sodium acetate and sodium citrate. Secondly, appropriate proportion nickel sulfate was dropped one by one into the mixture and then water bath heating at $60^{\circ} \mathrm{C}$ for $50 \mathrm{~min}$.

\section{Electrode preparation}

Prior to use, the glassy carbon electrode was carefully polished with chamois leather containing 0.05 $\mu \mathrm{m} \mathrm{Al}_{2} \mathrm{O}_{3}$ slurry and then ordinal ultrasonically cleaned in ethanol and distilled water. $10.0 \mathrm{mg}$ of $\mathrm{NiOx} / \mathrm{N}-\mathrm{CNTs}$ was dispersed with the aid of ultrasonic agitation in $10 \mathrm{~mL} \mathrm{~N}, \mathrm{~N}$-dimethylformamide to give a $1.0 \mathrm{mg} / \mathrm{mL}$ black suspension. The $\mathrm{NiOx} / \mathrm{N}-\mathrm{CNTs} / \mathrm{GC}$ electrode was prepared by dropping 20 $\mu \mathrm{L}$ of the suspension on the clean GC electrode surface and then evaporating the solvent in air. The CNTs /GC and N-CNTs /GC electrodes were prepared by the similar method.

\section{Electrochemical Measurements}

Cyclic voltammetry $(\mathrm{CV})$ was performed at room temperature in $0.1 \mathrm{~mol} . \mathrm{L}^{-1} \mathrm{KOH}$ solutions, which were purged with high purity nitrogen or oxygen for at least 10 min prior to each measurement. The modified electrode acted voltammetric cycles from $0.2 \mathrm{~V}$ to $-1.2 \mathrm{~V}$ at a scan rate of $50 \mathrm{mV} . \mathrm{s}^{-1}$.

\section{RESULTS AND DISCUSSION}

\section{Characterization of nickel oxide/ nitrogen-doped carbon nanotubes}

Figure. 1 shows the SEM images for the CNTs, N-CNTs and the NiOx/N-CNTs. It is clear from the SEM images in Figure 1 that the surface of CNTs has been coated with nickel oxide.

Figure 2 shows the Energy Dispersive Spectrometer (EDS) images for the N-CNTs and the $\mathrm{NiOx} / \mathrm{N}-\mathrm{CNTs}$. It showed that the elemental composition of this material. The atomic ratio of nitrogen is $14 \%$ and that of oxygen is $86 \%$ (Fig. 2 A). The EDS image show that the NiOx/N-CNTs is composed of nitrogen, oxygen and nickel element (Figure $2 \mathrm{~B}$ ).

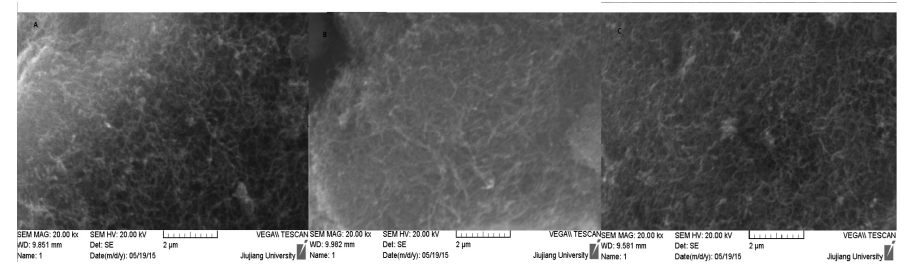

Figure 1. SEM image of the CNTs(A), N-CNTs(B) and the NiOx/N-CNTs(C)

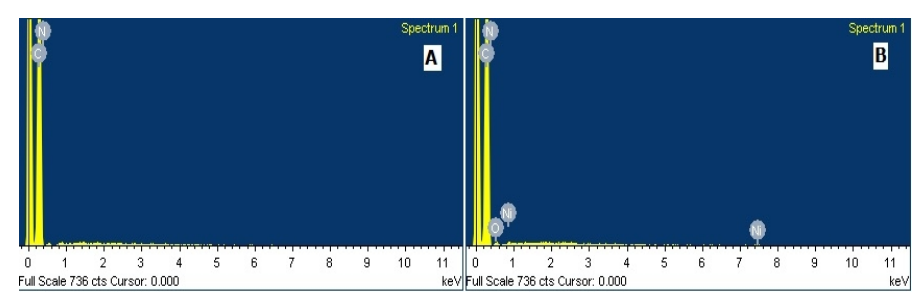

Figure 2. EDS image of the N-CNTs(A) and the NiOx/N-CNTs(B)

Figure 3 is a comparison of the infrared spectra of N-CNTs and CNTs. It showed that 1300$1100 \mathrm{~cm}^{-1}$ has $\mathrm{C}-\mathrm{C}$ bond stretching vibration peaks, $2000-1500 \mathrm{~cm}^{-1}$ has the double bonds $\mathrm{C}=\mathrm{C}$ stretching vibration peaks. The change of the peak of the $1300-1100 \mathrm{~cm}^{-1}$ and $2000-1500 \mathrm{~cm}^{-1}$ region showed the appearance of $\mathrm{C}-\mathrm{N}$ bond and $\mathrm{C}=\mathrm{N}$ bond.

\section{Electrocatalytic Activity for Oxygen Reduction Reaction}

Cyclic voltammetry was used to investigate the electrocatalytic activity of the nickel oxide/ nitrogendoped carbon nanotubes. Figure 4 showed the cyclic voltammograms of the NiOx/N-CNTs in 0.1 mol. $\mathrm{L}^{-1} \mathrm{KOH}$ solutions, saturated with or without $\mathrm{O}_{2}$. There have no obvious redox current peaks when the oxygen was removed (Fig. 4 a). However, there has a very large reductive current peak at $0.37 \mathrm{~V}$ in the air saturated $0.1 \mathrm{~mol} . \mathrm{L}^{-1} \mathrm{KOH}$, which corresponds to the $\mathrm{O}_{2}$ reduction reaction. (Fig. 4 b). 


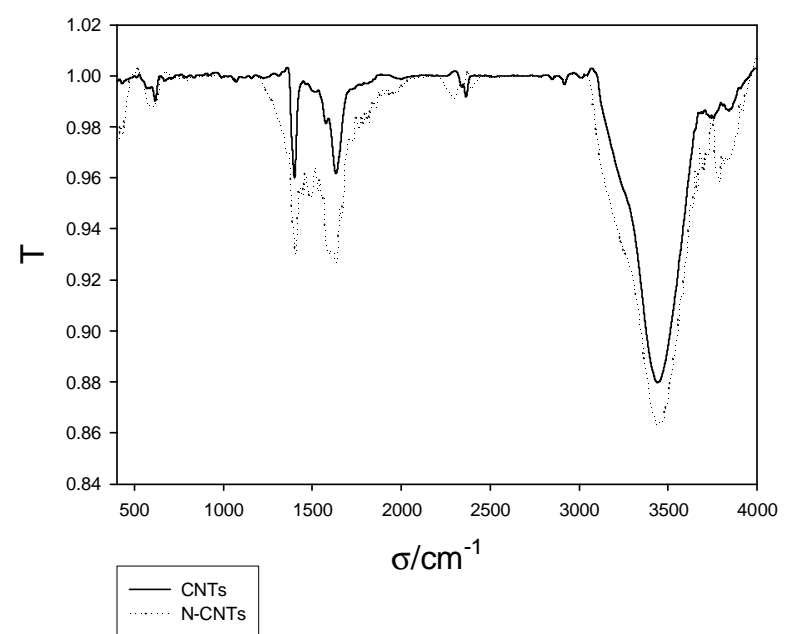

Figure 3. IR image of the CNTs and N-CNTs

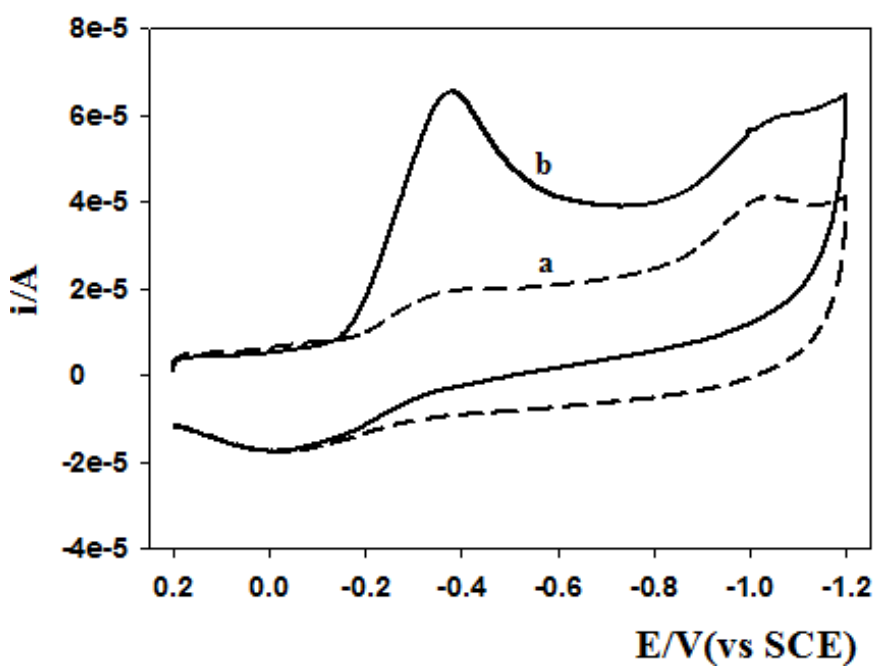

Figure 4. Cyclic voltammograms of NiO/N-CNTs, for the oxygen reduction reaction in $0.1 \mathrm{~mol} . \mathrm{L}^{-1}$ $\mathrm{KOH}$ solutions with (b) or without $\mathrm{O}_{2}(\mathrm{a})$

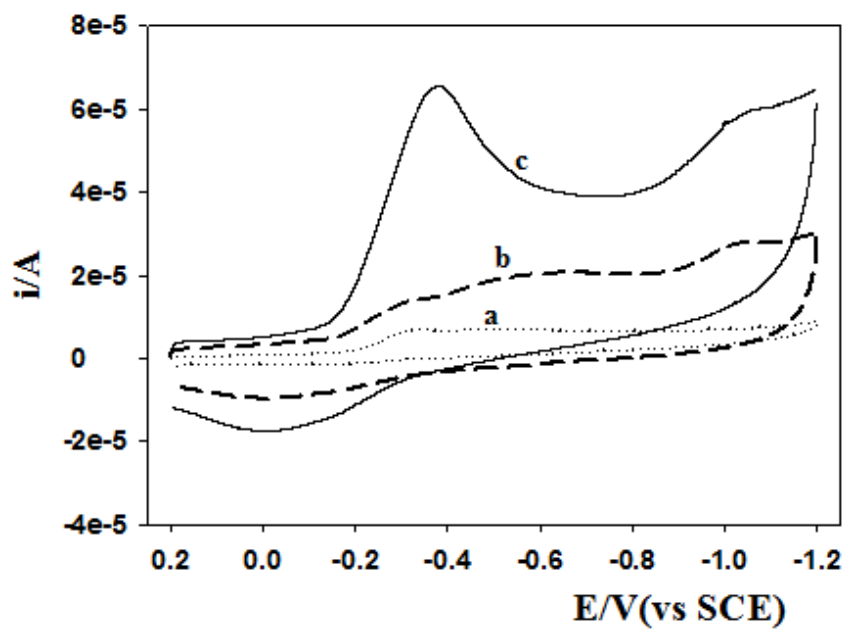

Figure 5. Cyclic voltammograms of (a) CNTs, (b) N-CNTs and (c) NiOx/N-CNTs, for the oxygen reduction reaction in 0.1 mol. $\mathrm{L}^{-1} \mathrm{KOH}$ solutions saturated with $\mathrm{O}_{2}$.

Figure 5 showed the cyclic voltammograms of the CNTs, N-CNTs and the NiOx/N-CNTs in 0.1 mol.L $\mathrm{L}^{-1} \mathrm{KOH}$ solutions, saturated with $\mathrm{O}_{2}$. Equal amounts of each catalyst were loaded on a glassy- 
carbon electrode. As shown in Figure 5, the current of the bare glassy carbon electrode (Fig. 5 a) is very low and that of the nitrogen doped carbon nanotube (Fig. $5 \mathrm{~b}$ ) is higher. After modification of nickel oxide, the electric current is higher than the nitrogen doped carbon nanotubes(Fig. $5 \mathrm{c}$ ). The reduction current of $\mathrm{NiOx} / \mathrm{N}-\mathrm{CNTs}(58 \mu \mathrm{A}$, Fig. $5 \mathrm{c})$ is five times larger than that of N-CNTs catalyst (Fig. $5 \mathrm{~b}$ ) and nine times larger than that of CNTs. The nickel oxide/ nitrogen-doped carbon nanotubes boasts a greater electrocatalytic activity to ORR and will be a potential catalytic material.

\section{CONCLUSIONS}

In this paper, we have reported a nickel oxide/ nitrogen-doped carbon nanotubes composite material via a simple chemical plating method. The electrochemical behaviour of the composite material for ORR has studied. The nickel oxide/ nitrogen-doped carbon nanotubes show electrocatalytic activity to ORR and may be a potential cathode material of the air battery.

\section{Acknowledgements}

This work was financially supported by scientific research project of Jiujiang University (2013kj04) and Key scientific research project of Jiujiang University (Pinghua YANG, 2014).

\section{References}

[1] Alexey Serov \& Chan Kwak. 2009. Review of non-platinum anode catalysts for DMFC and PEMFC application. Applied Catalysis B: Environmental 90(3-4): 313-320

[2] Kuanping Gong, Ping Yu, Lei Su, Shaoxiang Xiong, and Lanqun Mao. 2007. Polymer-assisted synthesis of manganese dioxide/carbon nanotube nanocomposite with excellent electrocatalytic activity toward reduction of oxygen. J. Phys. Chem. C 111 (5): 1882-1887

[3] Kurak K A, Anderson A B. 2009. Nitrogen-treated graphite and oxygen electroreduction on pyridinic edge sites. Journal of Physical Chemistry C 113(16): 6730-6734.

[4] Wang Z, Jia R, Zheng J, et al. 2011. Nitrogen-promoted self-assembly of N-doped carbon nanotubes and their intrinsic catalysis for oxygen reduction in fuel cells. Acs Nano 5(3):1677-1684.

[5] Winter M. \& Brodd R. J. 2004. What are batteries, fuel cells, and supercapacitors? Chemical Reviews 104(10): 4245-4269

[6] Yu D., Qiang Z.\& Dai L. 2010. Highly efficient metal-free growth of nitrogen-doped singlewalled carbon nanotubes on plasma-etched substrates for oxygen reduction. Journal of the American Chemical Society 132(43):15127-15129 